\title{
GBEP
}

\section{Anísio Teixeira e a Psicologia: o valor da mensuração}

Karen Fernanda Bortoloti

Marcus Vinicius da Cunha

\section{Resumo}

Analisa as ideias e a atuação de Anísio Teixeira nos anos 1920 e 1930, focalizando as suas concepções acerca do valor da mensuração para a renovação educacional no Brasil. Considerando que o pensamento e as práticas de Teixeira devem ser compreendidos no contexto em que se desenvolveram, apresenta um histórico da inserção dos saberes psicológicos na educação, com especial atenção para a adesão do movimento escolanovista à Psicometria. Conclui que, ao defender o uso da mensuração, Teixeira se manteve fiel à meta da Escola Nova que exigia diagnosticar cientificamente o universo escolar, o que se fazia necessário para responder à crescente demanda por escolarização e às deficiências das instituições de ensino brasileiras.

Palavras-chave: história da educação brasileira; Escola Nova; Anísio Teixeira; Psicologia; Psicometria. 


\section{Abstract \\ Anísio Teixeira and Psychology: the value of measurement}

This article analyzes the ideas and the work of Anísio Teixeira in the 1920s and 1930s, focusing on his views about the value of measurement for educational reform in Brazil. Considering that the thinking and practices of Teixeira should be understood in the context in which it was developed, the study presents the history of the presence of psychological knowledge in education, with special attention to the entrance of the Psychometrics in the New School movement. The paper concludes that, by defending the use of measurement, Teixeira has remained true to the goal of the New School that required to diagnoses scientifically the school universe, which was necessary to respond to the growing demand for schooling and the educational disabilities of the Brazilian educational institutions.

Keywords: History of Brazilian Education; New School; Anísio Teixeira; Psychology; Psychometrics.

\section{Introdução}

Desde o final do Império e o início do período republicano, o debate sobre as transformações educacionais necessárias ao Brasil tornou-se uma constante nos meios políticos e intelectuais. As contendas repercutiram especialmente nas reformas realizadas por Benjamin Constant nos anos 1890 (Lourenço Filho, 1953) e nos movimentos denominados "entusiasmo pela educação" e "otimismo pedagógico", favoráveis à ampliação do acesso aos bancos escolares e à busca por novos métodos de ensino (Veiga, 2007).

As sucessivas crises dos primeiros anos da República levaram significativa porção da intelectualidade a conceber a necessidade de modificar a sociedade, rompendo com a influência das ideias positivistas que predominavam no campo educacional escolar (Carvalho, 1989). Diversos projetos político-educativos ofereceram resposta aos obstáculos que se interpunham ao desejado progresso da sociedade; em seu bojo desenvolveu-se certa concepção do povo brasileiro e o desejo de instaurar a modernidade, isto é, a "civilidade, a racionalidade, a urbanidade, a disciplina de uma sociedade capitalista" (Nunes, 2000, p. 11).

Os educadores passaram a ocupar lugar de destaque nesse contexto, legitimando a sua esfera de atuação por intermédio da crescente valorização da escola como lugar de formação do homem brasileiro. Mesmo pertencendo a diferentes correntes de pensamento, praticamente todos 
partilhavam a crença na possibilidade de transformar a sociedade por meio do aprimoramento do ensino, o que os posicionou como liderança moral da sociedade (Xavier, 1999).

A historiografia reconhece que o auge desse processo ocorreu nos anos 1920 e no início da década seguinte, quando se articulou o movimento denominado Escola Nova, que teve as suas formulações gerais expressas no Manifesto dos Pioneiros da Educação Nova, em 1932. Um dos personagens de maior relevo nesse campo foi Anísio Teixeira, cuja trajetória de vida e profissional confunde-se com os mais importantes eventos e instituições educacionais no país, desde aquela época até o final da década de 1960.

No presente trabalho, abordaremos um assunto específico, ainda pouco explorado na historiografia, concernente às ideias e à atuação de Teixeira no âmbito da renovação educacional: o valor da mensuração propiciada pelo emprego dos recursos teóricos e técnicos da Psicologia, tendência que caracterizou o movimento escolanovista não só no Brasil como em outros países.

Entendemos que o pensamento e as práticas de Anísio Teixeira devem ser compreendidos no contexto em que se desenvolveram, pois os seus posicionamentos refletem as controvérsias e os anseios de seu tempo. Por isso, para elucidar as concepções anisianas acerca do tema aqui em pauta, traçaremos primeiramente um histórico da inserção dos saberes psicológicos na educação, com especial atenção para a adesão do escolanovismo brasileiro à Psicometria.

Procuraremos mostrar que, ao defender o uso da mensuração, Teixeira se mantinha fiel à meta da Escola Nova que exigia diagnosticar cientificamente o universo da escolarização formal, o que se fazia necessário para responder à crescente demanda pela escola, instituição cujas deficiências eram notórias, "tanto em termos qualitativos como quantitativos", tornando urgente a intervenção dos poderes públicos (Nunes, 2000, p. 352).

\section{A Psicometria na educação}

A discussão sobre a escola brasileira a partir da segunda década do século 20 refletia os problemas urbanos mais urgentes do país, ocasionados pela situação precária das habitações, pela ausência de saneamento básico, pelo desemprego e consequente marginalização, bem como pelas condições étnicas do povo. As escolas deveriam atender aos interesses da nação, pois eram vistas como os lugares mais adequados à formação do espírito moderno nas novas gerações (Nunes, 2007). A nova sociedade que então se arquitetava exigia uma nova escola, norteada por novos objetivos, nova linguagem e novos espaços de aprendizagem. Cabia às instituições de ensino comandar a construção de uma sociedade ordenada, asseada, laboriosa e uniformizada. 
Os ditos males nacionais que, segundo o pensamento vigente, impediam a modernização do país eram metaforicamente apresentados na figura de um povo doente, cuja cura seria comandada pela atuação de diversos profissionais - médicos, engenheiros e educadores (Herschmann; Pereira, 1994). A ignorância do povo era evidenciada pelos índices de analfabetismo e pelas endemias, símbolos da resistência perante a modernidade. Os intelectuais acreditavam que o vínculo da ciência com a educação garantiria o acesso do povo à essência nacional, auxiliando na superação da herança imposta por nosso passado colonial.

Houve diferentes interpretações da necessidade de modernização do país, bem como das formas de atingi-la. De modo geral, acreditava-se na urgência de desarticular a todo custo nosso perverso legado histórico. Se havia relativo consenso quanto a isso, o mesmo não ocorria quanto aos projetos sobre como realizar a almejada modernização. Para os que se denominavam higienistas, a higienização e a moralização, facilitadas pelo processo de escolarização, seriam suficientes para transformar o país. Os eugenistas, por sua vez, igualmente favoráveis ao auxílio da educação, raciocinavam com base na problemática étnica, relativa ao aprimoramento racial do homem brasileiro, o que ultrapassava a esfera das medidas higienizadoras (Stancik, 2005).

Para os higienistas, a solidariedade entre higiene e educação seria a verdadeira fonte da civilização e do bem estar. A colaboração com as instituições de ensino tornou-se possível, especialmente durante os anos 1920, quando a escola ampliou seu raio de ação, agregando outras tarefas e responsabilidades sociais (Nagle, 2001; Campos, 2008). As práticas higienistas objetivavam não apenas o saneamento físico, mas também o exame mental da população, no intuito de compreender os problemas que, ao longo dos séculos, culminaram no atraso da nação.

O movimento da higiene mental contribuiu para a aproximação entre a Psicologia e a Educação, ao propor o uso intensivo dos testes de nível mental como instrumento de diagnóstico psicológico. Associados à higienização, os conhecimentos oriundos da Psicologia seriam poderosos auxiliares na busca por medidas profiláticas e disciplinares tidas como fundamentais para a modernização. A Psicologia seria uma importante aliada na cruzada desenvolvimentista brasileira, associação que fortalecia o ideário da racionalidade científica então vigente (Campos, 2008; Nunes, 2000).

De forma distinta, os simpatizantes das teses eugênicas de branqueamento e sobrevivência do mais forte pregavam que as raças inferiores, como eram chamados os negros e os mestiços, não sobreviveriam às dificuldades impostas pela pobreza, o que remetia à necessidade de revigoramento da raça (Masiero, 2002). O termo raça, envolto pela noção de aprimoramento e alcance de uma suposta superioridade, floresceu nos primeiros anos do século 20 (Mosca, 1975). O principal responsável pela articulação das ideias eugênicas foi Francis Galton, que na obra Hereditary genius, de 1869, manipulou as concepções de Darwin para justificar o aprimoramento das raças e a seleção dos mais fortes (Masiero, 2002). 
A abordagem de Galton levava à crença de que o atraso de certos países ou povos era consequência direta da origem étnica ou da miscigenação que contaminava as raças puras. Os partidários brasileiros da eugenia acreditavam que o Brasil se encontrava em estágio inferior do processo civilizatório devido à mistura de raças aqui predominante, sendo a única saída o embranquecimento da população.

Tanto higienistas quanto eugenistas utilizavam os saberes psicológicos que então se estruturavam, visando justificar os seus próprios posicionamentos. Com a possibilidade de verificação das diferenças individuais por meio da mensuração da inteligência e da análise de tendências comportamentais, a Psicologia corroborava a afirmação de que uma sociedade moderna só se pode construir por meio da investigação e do reparo dos males provocados pelas raças inferiores (Skidmore, 1976; Campos, 2008; Marques, 2002). Tratava-se de dar um formato ao país até então amorfo, modificando substancialmente o povo para viabilizar a verdadeira nação.

Foi no ambiente permeado pelas teses higienistas e eugenistas que se desenvolveu a ânsia modernizadora de intelectuais e educadores brasileiros, levando a educação ao patamar de fator decisivo na edificação do novo país. Médicos e educadores acreditavam que a escola deveria aprimorar técnicas voltadas à formação de homens inteligentes e sadios (Gondra, 2002). O homem bronco e doente era passível de recuperação, bastando que fosse retirado do abandono em que se encontrava e curado das doenças que o paralisavam.

Bastava que a educação se apoiasse na Medicina e na Psicologia que, recém-chegada ao país, prometia congregar os saberes médicos, uma filosofia moral e os métodos quantitativos classificatórios. Incutindo hábitos de trabalho adequados às necessidades do país, a educação poderia auxiliar na formação e colocação dos trabalhadores, levando-os a contribuir efetivamente para o progresso nacional mediante a adoção de hábitos corretos e saudáveis condizentes com uma sociedade civilizada. Os educadores tornaram-se convictos de que o emprego dos conhecimentos provenientes das disciplinas científicas era fundamental para o bom exercício de seu ofício.

Assim, a mais relevante contribuição para a afirmação da Psicologia como ciência no Brasil veio da educação, campo em que atuaram os seus mais destacados divulgadores (Antunes, 2005; Nunes, 1998). A nova ciência fortaleceu-se com o advento das Escolas Normais, constituindo primeiramente uma seção específica de outras disciplinas, tornando-se posteriormente disciplina autônoma. O progresso das instituições de formação de professores levou à consolidação dos vínculos entre pedagogia e estudos psicológicos. Passaram a integrar os manuais de Pedagogia autores como Spencer, que colocava o desenvolvimento infantil no cerne da evolução da espécie, e Compayré, que enfatizava a cientificidade da Psicologia (Massimi, 1990). A penetração dos conhecimentos psicológicos no pensamento brasileiro vinha eliminar o discurso metafísico, em prol de uma abordagem científica (Cunha, 1995). 
A Psicologia sempre esteve intimamente associada ao fornecimento de recursos para a avaliação do rendimento e o aumento da eficiência (Lourenço Filho, 1953). A vertente denominada Psicometria ou Psicologia Experimental teve início no século 19, no momento em que a estruturação da Psicologia como ciência independente requeria o uso de métodos próprios de pesquisa (Gould, 1999). Os estudos que analisavam a natureza humana buscaram inspiração nas ciências físicas e biológicas, levando a Psicologia a superar o estágio pré-científico para se constituir como disciplina empírica, uma ciência totalmente avessa a qualquer teorização metafísica, apoiada na observação e na experimentação. O aprimoramento dos métodos quantitativos tornou a Psicometria praticamente hegemônica na área (Massimi, 1990; Walger, 2006).

O primeiro laboratório de Psicometria foi criado em 1870 no Instituto Experimental de Psicologia da Universidade de Leipzig, Alemanha, pelo médico Wilhelm Wunt (Brozek; Guerra, 1996). Em 1884, Galton criou um laboratório de antropometria em Londres, onde elaborou testes que visavam revelar as diferenças intelectuais por meio de métodos estatísticos (Walger, 2006). Alfred Binet e Theodore Simon foram os principais divulgadores dessa tendência, ao elaborarem o primeiro teste de inteligência de repercussão internacional. Seus trabalhos contribuíram para o desenvolvimento das escalas de inteligência e do conceito de idade mental, posteriormente denominado Quociente Intelectual - QI (Campos, 2008).

Vinda da Europa no início do século 20, a Psicometria começou a se firmar no Brasil especialmente com a estruturação dos laboratórios pedagógicos. Por determinação do diretor da Instrução Pública do Distrito Federal, Medeiros de Albuquerque, nosso primeiro Laboratório de Psicologia Experimental foi instalado em 1906 no Pedagogium, museu pedagógico criado em 1890 com o objetivo de nortear as reformas educacionais exigidas pela República (Penna, 1985). Planejado por Binet, o laboratório recebeu do médico Manuel Bonfim impulso notável, tornando-se um local para o desenvolvimento de subsídios para o trabalho dos professores. Bonfim foi também responsável pela ruptura com as teorias raciais, propondo a análise das raízes históricas do país e do povo e buscando compreender os traços da constituição psíquica individual (Bonfim, 2003).

Em 1907, Juliano Moreira criou o segundo Laboratório de Psicologia Experimental, tendo por objetivo analisar as características étnicas de pacientes hospitalizados (Penna, 1985). Em 1909, o italiano Clemente Quaglio organizou o Gabinete de Psicologia do Estado de São Paulo, anexo à Escola Normal da Praça, na capital, no qual se utilizou o exame das funções psicológicas de crianças. Em 1911, a pedido de Oscar Thompson, diretor da Instrução Pública paulista, Quaglio investigou os caracteres da infância anormal por meio de testes, utilizando a escala métrica da inteligência de Binet-Simon (Monarcha, 1999).

O médico italiano Ugo Pizzoli também estruturou laboratórios de Psicometria no Brasil, para que os futuros docentes acompanhassem o real 
desenvolvimento dos estudantes (Lourenço Filho, 1953). Pizzoli ministrou cursos sobre o uso de testes anamnésticos, físicos, antropológicos, fisiológicos e psicológicos e exames "somato-antropológicos, estesiometria e estesioscopia", incentivando o uso de medidas antropométricas e sensoriais (Antunes, 2005, p. 79). Com assessoria de Quaglio e Pizzoli, Thompson organizou em 1916 o Serviço de Inspeção Médico-Escolar, viabilizando o ingresso dos médicos no reduto dos educadores e contribuindo para amplificar o movimento dos testes.

A Psicometria, então, passou a constituir um dos pilares científicos da transformação educacional do país. Em meados de 1930, o Laboratório da Colônia de Psicopatas do Engenho de Dentro, sob a direção do polonês Waclaw Radecki, foi incorporado à Universidade do Brasil, favorecendo a institucionalização da Psicologia nos meios acadêmicos (Penna, 1985). Outros personagens fundamentais para consolidar esse processo foram Ulysses Pernambucano, que organizou o Instituto de Psicologia de Pernambuco (Antunes, 2005; Campos, 2008), e Helena Antipoff, que criou a Escola de Aperfeiçoamento Pedagógico de Belo Horizonte (Antunes, 2005), a Sociedade Pestalozzi de Minas Gerais e a Fazenda do Rosário, escola modelo para a educação de crianças anormais e a preparação de professores e psicólogos (Campos, 2008).

O crescente interesse pela aplicação da Psicologia na racionalização da administração escolar favoreceu a implantação de serviços de Psicologia sediados em instituições educacionais, como a Escola de Aperfeiçoamento de São Paulo (Campos, 2008), cuja atividade inspirou em 1931 a criação de um curso de aperfeiçoamento de docentes no Instituto Pedagógico de São Paulo (Lourenço Filho, 1954). Ao longo da década de 1930, os profissionais dessas duas instituições realizaram inúmeros trabalhos de análise de desenvolvimento mental, aptidões e interesses, buscando auxiliar na organização de classes escolares e na orientação educacional (Campos, 2008).

Um pesquisador importante para a difusão da Psicometria no Brasil foi Isaías Alves que, após especializar-se no Teachers College da Universidade de Columbia, aplicou, revisou e adaptou testes psicológicos e pedagógicos, estudou o desenvolvimento psicológico de crianças em fase pré-escolar e foi o primeiro a adaptar os testes Binet-Simon à população brasileira. Colaborador de Anísio Teixeira desde os anos 1920, Alves foi responsável pela instalação do Instituto Normal na Bahia, contribuindo com a publicação de obras de referência na área da educação. Durante a administração de Teixeira na Instrução Pública do Distrito Federal, Alves assumiu a chefia do Serviço de Testes e Medidas, produzindo estudos sobre a eficácia da mensuração psicológica e elaborando instrumentos mais adequados às especificidades nacionais (Walger, 2006).

Manuel Bergström Lourenço Filho foi o mais expressivo representante do elo entre o movimento de renovação educacional e a Psicologia. Após comandar a reforma do ensino no Ceará, Lourenço Filho dedicou-se à educação popular e à alfabetização, promovendo a aplicação de testes de inteligência e maturidade intelectual na Escola Normal de Piracicaba, 
o que foi posteriormente reproduzido em escolas da capital paulista e no Rio de Janeiro. Em 1925, Lourenço Filho reativou o Laboratório de Psicologia Experimental da Escola Normal da Praça (Monarcha, 2001) e, ao assumir a Diretoria de Ensino do Distrito Federal, em 1930, implantou o Serviço de Psicologia Aplicada, que marcou definitivamente a presença da Psicometria na educação nacional (Monarcha, 2009; Massimi, 1990).

Os Testes ABC para a verificação da maturidade necessária à aprendizagem da leitura e da escrita, elaborados por Lourenço Filho e publicados em 1934, buscavam identificar a variedade mental com base no conceito de maturação, propiciando a classificação dos anormais, a discriminação de temperamento e a identificação de aptidões (Monarcha, 2001). O instrumento aferia a maturidade para a leitura e a escrita e, uma vez aplicado em alunos dos anos iniciais da escola básica, fornecia o retrato inicial de cada grupo de alunos, permitindo a organização mais equilibrada das classes escolares (Lourenço Filho, 1953).

\section{A Psicometria na Escola Nova}

Ainda que a Psicologia não estivesse plenamente constituída como campo autônomo do saber no início do século 19, foi notório o uso de concepções psicológicas no discurso de intelectuais brasileiros desde o período colonial, principalmente por intermédio das teses da área médica. Apesar da influência das ideias europeias, as concepções norteamericanas foram marcantes, pois foi nos Estados Unidos que imperou a tendência de recorrer aos métodos das ciências naturais para incrementar os conhecimentos da Psicologia.

O florescimento da Psicologia Experimental e as discussões acerca de novos métodos de ensino naquele país atraíram muitos intelectuais brasileiros, em diferentes momentos de nossa história. Na primeira metade do século 20, estudantes brasileiros foram ao Teachers College da Universidade de Columbia, que, a partir de 1910, passou a oferecer cursos de formação docente articulando programas que visavam aprimorar a qualificação de professores e gestores educacionais. A instituição tornou-se referência na área devido a seus docentes e pesquisadores altamente qualificados, agregando o que havia de mais moderno e científico no âmbito da Pedagogia (Warde, 2002).

A reestruturação curricular de 1910 conferiu sensível notoriedade à Psicologia Experimental no Teachers College, mas a vertente mensuracionistas não era hegemônica. Desde 1921, tornou-se evidente a divergência entre os dois intelectuais daquela instituição, John Dewey e Edward Thorndike, o que influenciou diretamente o movimento de renovação educacional naquele país, levando a educação progressivista a expressar um dualismo que ultrapassou os muros da Universidade e atingiu as escolas públicas (Labaree, 2005).

De um lado, Dewey, partidário do progressivismo pedagógico, e de outro, Thorndike, defensor do progressivismo administrativo. Ambos 
haviam percorrido caminhos acadêmicos semelhantes, seguindo a trilha do Pragmatismo de Willian James; ambos acreditavam no desenvolvimento das capacidades dos alunos e criticavam duramente o currículo tradicional que não permitia a valorização do estudante e inviabilizava a aprendizagem realmente significativa para a vida (Warde, 2002).

Apesar da notoriedade alcançada em diversas áreas, inclusive na Psicologia, Dewey distanciou-se discretamente da vida acadêmica, deixando o caminho livre para a consagração de Thorndike. Quando a maioria dos estudantes brasileiros frequentou o Teachers College, Dewey já vinha se afastando da atividade docente e Thorndike tornava-se o centro das atenções em assuntos que envolviam a pesquisa educacional (Warde, 2002). Os partidários do progressivismo administrativo introduziram os testes de capacidade intelectual, no intuito de classificar os alunos e direcioná-los a classes mais adequadas às suas características, opção que se opunha aos defensores do progressivismo pedagógico, que preferiam destacar a capacidade do aluno para aprender, recusando-se a mensurar diferenças intelectuais (Labaree, 2005).

Os pressupostos do progressivismo administrativo ganharam a adesão dos gestores porque a sua mensagem de reforma educacional garantia maior eficiência na organização e administração das escolas. Suas qualidades utilitárias foram assimiladas mais facilmente do que a visão romântica dos defensores do progressivismo pedagógico. Os discípulos de Thorndike enfatizavam as exigências da vida profissional, não os interesses pessoais dos estudantes; a aprendizagem de assuntos específicos, não o aprender a aprender; a escola como preparação direta para a vida produtiva, não como lugar de desenvolvimento das potencialidades da infância (Labaree, 2005).

O Teachers College recebeu intelectuais como Isaías Alves, Lourenço Filho, Anísio Teixeira e Noemy da Silveira, os quais, tendo em vista a necessidade de racionalização do trabalho docente no Brasil, contribuíram para que os testes se tornassem parte importante da cultura escolar brasileira entre os anos 1920 e 1930. A mensuração estabeleceu-se como ferramenta de grande utilidade para promover a regulação dos alunos nas salas de aula, objetivo da maior relevância devido ao número crescente de matrículas, o que exigia novas formas de garantir a permanência e o sucesso de todos (Nunes, 2000).

Com o avanço do ideário renovador, evidenciou-se a tendência de privilegiar "os resultados observáveis do processo de ensino, o que se materializou no grande incentivo à utilização de técnicas de medida e controle do trabalho docente e do rendimento escolar" (Cunha, 1995, p. 81). A Psicologia viria contribuir para "libertar a tarefa educativa de uma concepção que a ligava a atributos subjetivos", afastando a intuição do âmbito da prática educativa e atribuindo características científicas à educação (Cunha, 1994, p. 65).

O grupo que ficou genericamente conhecido como escolanovista levou para o interior das escolas as descobertas da Psicologia, ciência que possuía os meios para a investigação objetiva das características infantis, 
o que viria auxiliar na realização plena dos atributos de cada indivíduo (Cunha, 1994). A nova ciência era capaz de descrever e administrar as variações psicológicas e organizar as classes segundo as capacidades intelectuais das crianças, além de colaborar na elaboração de métodos de ensino adequados aos processos de desenvolvimento infantil.

Partilhando do ímpeto modernizador que tomava conta do país nas primeiras décadas do século 20, o movimento escolanovista compreendia a necessidade de construir um novo homem brasileiro, devendo a educação contar com os saberes científicos da Psicologia. A nova ciência era vista como parceira no processo de transformar a educação, exigência vital para a mudança do país. Amparados nas orientações advindas da Psicologia e incorporadas pelas novas diretrizes pedagógicas, os professores deviam conceber seus alunos como indivíduos dotados de personalidade (Cunha, 1995).

Os anos de 1920 e 1930 representaram o fortalecimento do movimento dos testes no Brasil porque os renovadores da educação assimilaram o valor da Psicometria no cumprimento de diversas metas educacionais, como a homogeneização das classes escolares, o progresso da leitura e da escrita, a identificação de deficiências mentais e distúrbios na aprendizagem e a verificação de aptidões. Viabilizando o conhecimento científico da criança, os testes permitiam o enquadramento dos alunos em categorias físicas, mentais e emocionais, permitindo a sua classificação em normais e anormais, estabelecendo graus de maturidade e identificando distúrbios de caráter (Monarcha, 2001; Carvalho, 1989; Nunes, 2000).

Em suma, a tendência mensuracionista da Psicologia conquistou a educação por intermédio dos partidários da Escola Nova porque, segundo o entendimento vigente na época, a Psicometria viabilizava o respeito ao desenvolvimento psicológico das crianças e, ao mesmo tempo, facilitava a organização racional das instituições de ensino e do trabalho docente, o que, por sua vez, contribuía decisivamente para realizar o ideal de colocar a educação a serviço do progresso do país.

\section{A Psicometria em Anísio Teixeira}

A familiaridade de Anísio Teixeira com a Psicometria teve início por volta de 1928, quando, ao dirigir a Instrução Pública da Bahia, organizou um curso intitulado Medidas da Inteligência e dos Resultados Escolares, ministrado por Isaías Alves com base no livro Teste individual de inteligência, de sua autoria, publicado em 1926. Anísio aproximou-se da vertente experimental da Psicologia por encontrar naqueles conceitos um modo de garantir a aplicação da ciência à educação - lema comum a todos os escolanovistas - e assim ampliar as possibilidades de sucesso das instituições de ensino.

Para compreender tal aproximação, é indispensável analisar as ideias de Teixeira acerca da ciência e das contribuições que os conhecimentos científicos poderiam oferecer à educação e à transformação social. Para ele, 
a ciência era crucial para a nova sociedade pretendida para o Brasil, pois permitiria a fundação de uma mentalidade pautada na noção de mudança, abrindo caminho para novas descobertas. A ciência viria substituir a religião e as explicações metafísicas, auxiliando na formação de um homem disposto a contribuir para a consolidação de uma sociedade fundada no fazer científico, afastando o predomínio da mentalidade retrógrada da elite (Barreira, 2000).

Teixeira (1969) acreditava que a ciência poderia instrumentalizar o avanço da educação, ao introduzir a análise objetiva, a investigação e a verificação dos fatos concernentes à esfera escolar. Tanto a Psicologia quanto os saberes sociológicos trariam elementos essenciais para a sistematização de técnicas e procedimentos para o progresso da prática educativa, viabilizando a verificação e comprovação dos meios instrucionais. A inserção do conhecimento científico na escola seria decisiva para reconstruir, com mais inteligência e cautela, as práticas e as políticas educacionais, o que viria contribuir para a edificação de uma educação realmente nova, transformadora; e a ciência experimental era a mais promissora em todos esses aspectos (Teixeira, 1997).

O pensamento de Teixeira não apresentou viradas bruscas, não houve vários Anísios ao longo das décadas, mas um pensador coerente que foi continuamente alicerçando as suas ideias e ações (Lovisolo, 1990). Esta afirmação de caráter geral pode ser aplicada às suas relações com a Psicologia, que foram sempre norteadas por uma ampla compreensão das responsabilidades sociais da educação - da mesma maneira, suas reflexões sobre o valor do indivíduo no ambiente escolar sempre foram guiadas por um pensamento que privilegiava a inserção da escola no contexto das potencialidades e limitações da vida social brasileira.

Exemplo disso encontra-se em um escrito de meados da década de 1920, no qual Teixeira (1924) pondera sobre as discussões acerca da escola única, tema fartamente discutido à época, especialmente por Carneiro Leão. Sua tese é que uma escola que almeje a uniformização do ensino pode ser prejudicial, não apenas às liberdades individuais, mas também ao desenvolvimento das capacidades singulares, pois nem todos os brasileiros necessitam do mesmo tipo de escola. Anísio afirma que a escola deve respeitar e trabalhar as capacidades individuais, mas sempre visando à formação de homens necessários para a transformação do país.

Considerações semelhantes encontram-se em dois documentos de 1925, intitulados Manuscrito sobre Assuntos Educacionais e Relatório da Inspetoria Geral do Ensino do Estado da Bahia, nos quais Teixeira ratifica sua proposta de que a escola seja diferenciada para atender às especificidades dos alunos, pois a expansão das oportunidades educacionais é a maneira mais eficaz de assegurar a todos o desenvolvimento das potencialidades e um lugar na sociedade que então se estruturava. Anísio critica os que acreditavam ser suficiente uma escola de ensino integral e uniforme, para garantir o desenvolvimento e a expansão das potencialidades individuais. Esse tipo de escola, diz ele, ocasiona o nivelamento intelectual, ignorando 
as particularidades dos alunos e produzindo segregação ainda maior do que a existente.

A defesa da diversidade e das particularidades individuais não era feita por Teixeira somente com base nos referenciais da Psicologia, mas tomando por princípio as necessidades reais do país. A escolarização devia ser universalizada, mas considerando as diferenças locais e as características do alunado de cada região (Teixeira, 1924). Só o correto conhecimento e aproveitamento das diferentes potencialidades individuais poderia colocar a escola em condições de contribuir com a expansão dos ideais democráticos.

Antes de estudar no Teachers College, no final dos anos 1920, Anísio Teixeira já via a educação como fenômeno complexo que engloba aspectos psicológicos e sociológicos a serem devidamente equacionados. A reforma do ensino baiano feita por ele em meados daquela década teve por objetivo reorganizar a escola elementar, que seria obrigatória e articulada aos demais níveis, incluindo o profissional. Sua intenção era proporcionar a qualificação dos mais aptos, valorizando as habilidades individuais em contraposição aos privilégios decorrentes das posições sociais, de modo a preparar os alunos para a vida "com senso prático de coragem, de iniciativa e de independência" (Teixeira, 1925, p. 11).

A análise dos textos de Teixeira anteriores a seus estudos no Teachers College evidencia que ele já era envolvido com a ideia de transformar o país por meio de novas práticas pedagógicas e políticas educacionais, para isso contando com as contribuições da Psicologia. A convivência com o modo de vida americano reforçou essa crença, oferecendo-lhe uma concepção de mundo naturalista e científica que rompeu definitivamente a interpretação mística jesuítica advinda de sua formação escolar inicial. Anísio tornou-se, então, "realmente libertado", não por adquirir, "em lugar de velhas certezas definitivas, novas certezas definitivas", mas por aprender "um processo, um método diferente de pensar e colocar problemas" (Viana Filho, 1990, p. 36).

Teixeira trouxe dos Estados Unidos uma concepção mais madura sobre a educação destinada a abrir novos caminhos para a vida das crianças brasileiras, desejava que a escola de lá fosse implantada aqui (Viana Filho, 1990). Maravilhou-se com os rumos da civilização moderna, tão cobiçada pelos brasileiros, percebeu que o espaço da criança na nova escola era muito diferente do que o reservado pela escola tradicional, à qual já se opunha, tomou consciência de que o fundamento da educação era a experiência - conceito fundamental da filosofia deweyana - em perfeita concordância com as tendências de cada criança, e que só isso poderia dar condições para o equilíbrio e a harmonia sociais (Teixeira, 2006).

Nos Estados Unidos, as concepções educacionais de Anísio Teixeira tornaram-se profundamente impregnadas pelo pensamento de John Dewey, mas o seu amadurecimento não foi somente no campo filosófico, pois incluía o reconhecimento do valor da medida para o progresso da educação. Lourenço Filho (1953, p. 317), que estudou no Teachers College naquela mesma época, atesta que a "psicotécnica da educação" 
foi divulgada no Brasil por intermédio de Anísio Teixeira, tornando-se a principal corrente da Psicologia a encontrar espaço no país.

No livro que escreveu ao retornar dos Estados Unidos, Teixeira (2006, p. 36) exalta a Psicologia como ciência capaz de auxiliar na real democratização da educação, por viabilizar a identificação das capacidades individuais e, assim, fazer com que cada indivíduo receba o que há de melhor para o aprimoramento de suas potencialidades. Educar, portanto, é "dirigir o educando com o seu pleno assentimento e a sua plena participação mental, para o exercício adequado de suas próprias tendências e atividades". Ao mencionar a reforma educacional ocorrida naquele país, Teixeira (2006, p. 77) reconhecia a relevância do "movimento de medição na escola, com os testes em aritmética, soletração, linguagem e álgebra etc.", associado à "determinação do valor social das habilidades dos conhecimentos escolares pelo estudo e classificação das atividades humanas".

No Brasil, o momento era propício para que ocorresse algo semelhante, uma vez que o país iniciava uma etapa de profundas transformações econômicas, o que favorecia a propagação das ideias que irradiavam dos principais centros europeus, como também - e especialmente, para Anísio - dos Estados Unidos. O momento favorecia a eliminação do tradicional divórcio entre as atividades escolares e as exigências da realidade, mal que fazia predominar uma "mentalidade formal e subjetiva" (Teixeira, 2006, p. 59).

A escola primária devia ser a pedra fundamental de toda a educação, coordenada pelo verdadeiro espírito democrático - tese que Teixeira defendeu por toda a sua vida, sob a marcante influência de John Dewey. O poder da nova escola deriva da possibilidade de serem criadas as condições ideais para o bom desenvolvimento do indivíduo, que será conquistado não por meio do treino das "faculdades mentais", que são "um mito"; a educação não se processa como o "treino do ginasta para adquirir certa e determinada habilidade", mas não se pode negar a existência de "tendências originais, de modos instintivos de ação baseados em ligações originais de neurônios do sistema nervoso central", que podem ser conhecidos e trabalhados pelos educadores, o que representa "uma conquista definitiva da Psicologia Experimental" (Teixeira, 2006, p. 43).

Analisando o ocorrido nos Estados Unidos, nesse mesmo livro Anísio Teixeira afirma que o cultivo da personalidade e a libertação das capacidades individuais, proporcionadas pela Psicologia, poderiam romper as barreiras econômicas ou nacionais, permitindo a participação mais livre e enriquecedora dos indivíduos nos movimentos de transformação da sociedade, em direção à democracia. Isso seria possível se fossem oferecidas oportunidades para o desenvolvimento das potencialidades de cada pessoa e o seu consequente posicionamento em uma função social. Os inquéritos escolares auxiliariam na "reconstrução científica do currículo" (Teixeira, 2006, p. 77), enquanto o espírito investigativo permitiria o planejamento racional da ação e a avaliação do trabalho realizado. 
Os resultados assim obtidos e os conhecimentos da infância, ambos oriundos da Psicologia, serviriam de base para um programa educacional progressivo, ofertando os meios para o enriquecimento da experiência do aluno. A determinação do valor social das habilidades e dos conhecimentos escolares, obtida pela aferição viabilizada pelos testes, responderia pela criação de condições ideais para o avanço da sociedade. A efetiva reorganização da escola dependia da análise de habilidades e problemas, bem como do exame das instituições e dos conceitos necessários à compreensão da vida contemporânea; uma vez apuradas objetivamente as principais dificuldades do aprender, o estudo das vocações e profissões seria finalmente efetivo (Teixeira, 2006, p. 78).

No prefácio que elaborou para Vida e educação, coletânea composta por dois textos de John Dewey, Anísio Teixeira (1959) destaca que a capacidade de aprendizado dos alunos pode ser medida, especialmente durante os primeiros anos escolares, quando os professores devem aproveitar o potencial e a plasticidade dos estudantes para direcionar o aprendizado. A análise das tendências individuais, portanto, constitui elemento central na realização das atividades educativas.

Após 1931, quando passou a dirigir a Instrução Pública do Distrito Federal, Teixeira direcionou a formação docente para o "exercício disciplinar do olhar", de maneira que os futuros professores aprendessem a analisar meticulosamente os alunos e, assim, aprimorar a sua própria atuação (Vidal, 1996, p. 239). Cabia aos laboratórios demonstrar as formas de ensino por meio da experimentação de novos métodos e da prática de ensino com as classes de aplicação, fazendo prevalecer o caráter experimental mediante dados relativos ao desenvolvimento mental das crianças, obtidos pelas professorandas.

Por meio da Divisão de Obrigatoriedade Escolar e Estatística e da Seção de Medidas de Eficiência Escolar, Anísio Teixeira utilizou largamente a estatística para unificar a rede de ensino carioca e aferir o trabalho realizado nas escolas (Nunes, 2000). Para ingressar como professoras no Instituto de Educação, as candidatas submetiam-se a testes de idade mental, além do exame para verificar eventuais "moléstias transmissíveis ou defeito físico incompatível com o exercício do magistério" (Vidal, 2001, p. 105)

Teixeira (1935, p. 4-5) defendia que a função dos testes era contribuir para a solução de problemas de aprendizagem, permitindo enfrentar o fracasso escolar por meio de meticulosa análise do desenvolvimento do estudante, processo que contém leis próprias que só podem ser cumpridas em condições normais adequadas. As crianças matriculadas recebiam acompanhamento médico e assistência alimentar, visando à melhoria do rendimento, para que todos atingissem os objetivos esperados. A Psicologia Experimental auxiliaria a interpretar os elementos de sucesso e de falha de cada criança, "bem como suas exibições de força e fraqueza a partir do exame do seu crescimento".

Anísio Teixeira concentrou-se na solução dos enigmas da heterogeneidade, da diferença e da irregularidade evidenciados pela 
presença de alunos das camadas menos abastadas que mostravam dificuldades de aprendizagem. Havia grande número de crianças com mais de sete anos de idade cursando o primeiro ano primário; do total de 7.632 matriculados em 1930, apenas 2.715 (35\%) estavam na série ideal. Era diante de tais problemas de natureza eminentemente social que Teixeira (1933) justificava a adoção dos testes de QI, vistos por ele como instrumento para aprimorar o rendimento dos alunos, tomando por base as suas condições reais e o respeito às suas características individuais. Os testes possibilitavam a homogeneização das classes escolares, única medida capaz de encaminhar a solução imediata do problema.

O projeto de Anísio aliava os resultados dos testes às medidas do aproveitamento escolar, tendo por meta reclassificar os alunos de acordo com as suas capacidades e, simultaneamente, propor novos programas de estudo em consonância com as características predominantes em cada grupo. A classificação dos alunos em grupos homogêneos, o tratamento das necessidades individuais e a organização dos níveis escolares segundo as especificidades das classes eram iniciativas fundamentais para a construção de uma escola verdadeiramente eficiente e justa (Teixeira, 1930, p. IX). A ausência dessas providências seria negar a abertura para uma escola realmente nova, conforme o modelo que Anísio conhecera nos Estados Unidos (Teixeira, 1933).

Os instrumentos de medida fornecidos pela Psicologia eram, portanto, indispensáveis na situação brasileira. Só a ciência, particularmente a ciência psicológica, poderia assegurar a eliminação do "regime da adivinhação e da opinião individual" (Teixeira, 1930, p. III-V). O emprego da Psicometria impediria o desperdício e evitaria desastres, por oferecer uma visão objetiva das capacidades e dificuldades dos alunos, suas aptidões e inaptidões, permitindo direcionar racionalmente seus estudos. Anísio Teixeira (1930, p. IX-XI) considerava que os testes representavam o ingresso da ciência na escola. "Mesmo alguns objetivos da educação podem ser, por eles, se não determinados pelo menos precisados, marcados e medidos".

Anísio sabia dos riscos inerentes à mensuração, se utilizada como a única forma de nortear a busca por uma escola verdadeiramente nova e democrática, e não desejava que o recurso à Psicometria conduzisse à perda de autonomia didática dos professores e à classificação preconceituosa dos alunos. Em 1934, abandonou o uso dos testes de QI por concluir que seus resultados eram imprecisos e perigosos (Nunes, 2000, p. 357). Teixeira (1930, p. XII-XIII) já havia registrado esse problema anteriormente, no prefácio à obra Os testes e a reorganização escolar de Isaías Alves, no qual escreveu que a utilização das escalas etárias como norma rígida, não apenas estatística, poderia prejudicar o trabalho dos professores, se os levasse a tomar os testes como modelo ou método para o ensino, e não como instrumentos de diagnóstico, limitando a educação a uma concepção fundamentada em "resultados imediatamente tangíveis e concretos".

Conforme se lê no referido prefácio, Anísio era favorável a uma linha de equilíbrio entre os resultados oriundos das várias formas de aferição 
e a construção de categorias de ordenação; os testes deveriam servir não apenas para classificar, mas principalmente para mobilizar as capacidades e habilidades dos sujeitos. Devia-se evitar que a medida conferisse à escola uma organização mecânica que a habilitasse a "manufaturar, como uma fábrica, produtos eficientes, mas vazios de cultura" - entendendo-se cultura "como o cultivo mais delicado e mais sutil da inteligência e do coração" (Teixeira, 1930, p. XV).

Anísio Teixeira acreditava na possibilidade de identificar os atributos individuais para prover o seu máximo aproveitamento "em prol do crescimento individual e da organização social" (Nunes, 2000, p. 358). Para ele, não havia "nada a dizer" aos que "têm medo de medir" por receio de que a medida possa "diminuir a beleza ou a poesia da vida", pois qualidades como "coragem, ou heroísmo, ou espírito de sacrifício" não perdem "a sua nobreza nem a sua beleza" quando medimos, "do mesmo modo que as flores não perderam o seu encanto com o desenvolvimento da botânica". Os testes, "como qualquer outra descoberta científica, não podem ser julgados pelas suas limitações", mas pela utilidade que propiciam; por esse critério, ninguém pode negar que os "novos instrumentos de medida mental e escolar" devam ser "bem julgados" (Teixeira, 1930, p. XV-XVI).

\section{Considerações finais}

Abordamos no presente trabalho as ideias e realizações de Anísio Teixeira relativas à mensuração psicológica como importante auxiliar no processo de renovação educacional no Brasil durante os anos 1920 e a primeira metade da década de 1930. Vimos que Teixeira, embora fosse um entusiasta dos testes, compreendia os problemas inerentes a esse recurso, cujos resultados, ao mesmo tempo que favoreciam uma visão objetiva do trabalho docente, poderiam impedir a aproximação entre a vida escolar e a vida real, gerando certa artificialidade e perpetuando a desigualdade entre os indivíduos. Anísio sabia que a medida não era suficiente para garantir a convivência na diferença, podendo isolar o anormal e acarretar desajuste ainda maior no interior do ambiente escolar.

A busca pelo equilíbrio entre a classificação e a mobilização das capacidades e habilidades individuais fez com que Anísio Teixeira procurasse algo além dos testes, algo que viesse auxiliar o sujeito no processo de construção do conhecimento (Nunes, 2000). Voltou-se, então, para outras possibilidades sugeridas pela própria Psicologia que auxiliassem na compreensão do indivíduo, não como objeto passível de medida. A aproximação com outras vertentes da ciência psicológica - como a Psicanálise, por exemplo - constitui um tópico especial na trajetória do educador baiano, a ser examinado em outro estudo, oportunamente.

Com o término do Estado Novo, em 1945, após praticamente dez anos de autoexílio por motivações políticas, Anísio Teixeira retomou sua posição de liderança no movimento de renovação educacional, assumindo 
a direção de importantes órgãos governamentais, como a Coordenação de Aperfeiçoamento de Pessoal de Nível Superior (Capes), o Instituto Nacional de Estudos e Pesquisas Educacionais (Inep) e o Centro Brasileiro de Pesquisas Educacionais (Xavier, 1999; Nunes, 2000). Nessa época, suas reflexões e práticas no campo educacional continuaram levando em conta as contribuições da Psicologia, mas o seu desenvolvimento foi guiado especialmente por referenciais sociológicos e antropológicos. Esse é mais um tópico da trajetória de Anísio a ser abordado em outro estudo, oportunamente.

\section{Referências bibliográficas}

ANTUNES, Mitsuko Aparecida Makino. A Psicologia no Brasil: leitura histórica sobre sua constituição. 4. ed. São Paulo: Unimarco, Educa, 2005.

BARREIRA, Luiz Carlos. Escola e formação da mentalidade do desenvolvimento no discurso político-pedagógico de Anísio Teixeira. In: SMOLKA, Ana Luiza Bustamante; MENEZES, Maria Cristina (Org.). Anísio Teixeira, 1900-2000: provocações em educação. Campinas: Autores Associados; Bragança Paulista: Universidade São Francisco, 2000.

BONFIM, Elizabeth de Melo. Contribuições para a história da Psicologia no Brasil In: JACÓ-VILELA, Ana Maria; ROCHA, Marisa Lopes;

MANCEBO, Deise (Org.). Psicologia social: relatos na América Latina. São Paulo: Casa do Psicólogo, 2003.

BROZEK, Josef S.; GUERRA, Erlani I. Que fazem os historiógrafos? Uma leitura de Josef Brozek. In: CAMPOS, Regina Helena de Freitas (Org.). História da Psicologia. São Paulo: Educ, 1996. p. 11-27. (Coletâneas da ANPEPP, n. 15).

CAMPOS, Regina Helena Freitas. História da Psicologia e História da Educação - conexões. In: VEIGA, Cynthia Greive; FONSECA, Thaís Nívia de Lima (Org.). História e historiografia da educação no Brasil. Belo Horizonte: Autêntica, 2008.

CARVAlHO, Marta Maria Chagas. A escola e a república. São Paulo: Brasiliense, 1989.

CUNHA, Marcus Vinicius. A dupla natureza da Escola Nova: Psicologia e Ciências Sociais. Cadernos de Pesquisa, São Paulo, n. 88, p. 64-71, fev. 1994. 
Anísio Teixeira e a Psicologia: o valor da mensuração

CUNHA, Marcus Vinicius. A educação dos educadores: da Escola Nova à escola de hoje. Campinas: Mercado de Letras, 1995.

GONDRA, José G. "Modificar com brandura e prevenir com cautela": racionalidade médica e higienização da infância. In: FREITAS, Marcos Cesar; KUHLMANN Jr, Moisés (Org.). Os intelectuais na história da infância. São Paulo: Cortez, 2002.

GOULD, Stephen Jay. A falsa medida do homem. Trad. Valter Lellis Siqueira. São Paulo: Martins Fontes, 1999.

HERSCHMANN, Micael M.; PEREIRA, Carlos A. M. (Org.). A invenção do Brasil moderno: medicina, educação e engenharia nos anos 20-30. Rio de Janeiro: Rocco, 1994.

LABAREE, David F. Progressivism, schools and schools of education: an American romance. Paedagogica Historica, v. 41, n. 1/2, p. 275-288, fev. 2005.

LOURENÇO FILHO, Manuel B. Psicologia educacional. In: KLINEBERG, Otto (Org.). Psicologia moderna. São Paulo: Agir, 1953.

LOURENÇO FILHO, Manuel B. A Psicologia no Brasil. In: AZEVEDO, Fernando (Org.). As ciências no Brasil. São Paulo: Melhoramentos, 1954.

LOVISOLO, Hugo. A tradição desafortunada: Anísio Teixeira, velhos textos e ideias atuais In: ALMEIDA, Stela Borges et al. (Org.) Chaves para ler Anísio Teixeira. Salvador: UFB, 1990.

MARQUES, Vera Beltrão. Raça e noção de identidade nacional: o discurso médico-eugenista nos anos 1920. In: SEIXAS, Jacy; BRESCIANI, Maria Stella; BREPOHL, Marion (Org.). Razão e paixão na política. Brasília: Universidade de Brasília, 2002.

MASIERO, André Luiz. "Psicologia das raças" e religiosidade no Brasil: uma intersecção histórica. Psicologia: Ciência e Profissão, Brasília, v. 22, n. 1, mar. 2002.

MASSIMI, Marina. História da psicologia no Brasil: da época colonial até 1934. São Paulo: Universitária e Pedagógica, 1990.

MONARCHA, Carlos. A Escola Normal da Praça: o lado noturno das luzes. São Paulo: Unicamp, 1999.

MONARCHA, Carlos. Lourenço Filho e a organização da Psicologia aplicada à educação. São Paulo: 1922-1933. Brasília: Inep, 2001. 
MONARCHA, Carlos. Brasil arcaico, Escola Nova: ciência e utopia nos anos 1920-1930. São Paulo: Unesp, 2009.

MOSCA, Gaetano. A doutrina do super-homem e as teorias racistas. In: MOSCA, Gaetano; BOUTHOUL, Gaston. História das doutrinas políticas. Rio de Janeiro: Zahar, 1975.

NAGLE, Jorge. Educação e sociedade na Primeira República. 2. ed. Rio de Janeiro: DP \& A, 2001.

NUNES, Clarice. Historiografia comparada da Escola Nova: algumas questões. Revista da Faculdade de Educação, São Paulo, v. 24, n. 1, jan./ jun. 1998.

NUNES, Clarice. Anísio Teixeira: a poesia da ação. São Paulo: Edusf, 2000.

NUNES, Clarice. (Des) encantos da modernidade pedagógica. In: LOPES, Eliana Marta Teixeira; FARIA FILHO, Luciano Mendes; VEIGA, Cynthia Greive (Org.). 500 anos de educação no Brasil. 3. ed. Belo Horizonte: Autêntica, 2007.

PENNA, Antonio Gomes. Sobre a produção científica do laboratório de Psicologia da colônia de psicopatas no Engenho de Dentro. História da Psicologia, Rio de Janeiro, n. 1, p. 81-97, 1985.

SKIDMORE, Thomas E. Preto no branco: raça e nacionalidade no pensamento brasileiro. Trad. de Raul de Sá Barbosa. Rio de Janeiro: Paz e Terra, 1976.

STANCIK, Marco Antonio. Os Jecas do literato e do cientista: movimento eugênico, higienismo e racismo na Primeira República. Publicatio, UEPG, Ponta Grossa, v. 13, n. 1, p. 45-62, 2005.

TEIXEIRA, Anísio. A propósito da Escola Única. Revista do Ensino, Salvador, v. 1, n. 3, 1924.

TEIXEIRA, Anísio. Manuscrito sobre assuntos educacionais. AT pi (TEIXEIRA, A.) 1924/1926 00.00/3, CPDOC/FGV, 1925. Disponível em: http://www.fgv.br/CPDOC/BUSCA/Busca/BuscaConsultar.aspx. Acesso em: jan. 2011.

TEIXEIRA, Anísio. Prefácio. In: ALVES, Isaías. Os testes e a reorganização escolar. Salvador: Nova Graphica, 1930.

TEIXEIRA, Anísio. Texto sobre o quociente de inteligência (QI) de alunos. AT pi (TEIXEIRA, A.) 1918/1930 00.00/2, CPDOC/FGV, 1933. 
Disponível em: http://www.fgv.br/CPDOC/BUSCA/Busca/BuscaConsultar. aspx. Acesso em: jan. 2011.

TEIXEIRA, Anísio. Texto sobre a educação infantil. (AT pi TEIXEIRA, A. 1924/1936 00.00/1, CPDOC/FGV), 1935. Disponível em: < http://www. fgv.br/CPDOC/BUSCA/Busca/BuscaConsultar.aspx > . Acesso em: jan. 2011.

TEIXEIRA, Anísio. A pedagogia de Dewey. In: DEWEY, John. Vida e educação. São Paulo: Companhia Editora Nacional, 1959.

TEIXEIRA, Anísio. Educação no Brasil. São Paulo: Nacional, 1969.

TEIXEIRA, Anísio. Educação para a Democracia: introdução à administração educacional. 2. ed. Rio de Janeiro: UFRJ, 1997.

TEIXEIRA, Anísio. Aspectos americanos da educação: anotações de viagem aos Estados Unidos em 1927. Rio de Janeiro: UFRJ, 2006.

VIANA FILHO, Luís. Anísio Teixeira: a polêmica da educação. Rio de Janeiro: Nova Fronteira, 1990.

VEIGA, Cynthia Greive. História da Educação. São Paulo: Ática, 2007.

VIDAL, Diana Gonçalves. Ensaios para a construção de uma ciência pedagógica brasileira: o Instituto de Educação do Distrito Federal (1932-1937). Revista Brasileira de Estudos Pedagógicos, Brasília, v. 77, n. 185, p. 239-258, jan./abr. 1996.

VIDAL, Diana Gonçalves. O exercício disciplinar do olhar: livros, leituras e práticas de formação docente no Instituto de Educação do Distrito Federal (1932-1937). Bragança Paulista: Universidade São Francisco, 2001.

WALGER, Américo Agostinho Rodrigues. Psicometria e educação: a obra de Isaías Alves. Tese de doutorado. São Paulo: Pontifícia Universidade Católica, 2006.

WARDE, Mirian Jorge. Estudantes brasileiros no Teachers College da Universidade de Columbia: do aprendizado da comparação. In: II Congresso Brasileiro de História da Educação, 2., 2002, Natal. Anais: história e memória da educação brasileira. Natal, 2002.

XAVIER, Libânia Nacif. O Brasil como laboratório: educação e ciências sociais no Projeto dos Centros Brasileiros de Pesquisas Educacionais (1950/1960). Bragança Paulista: Universidade São Francisco, 1999. 
Karen Fernanda Bortoloti, doutoranda em Educação Escolar na Faculdade de Filosofia, Ciências e Letras de Araraquara (FCLAR/Unesp), é professora do Centro Universitário Sistema Educacional Brasileiro (UniSEB).

kfbortoloti@gmail.com

Marcus Vinicius da Cunha, doutor em História e Filosofia da Educação pela Universidade de São Paulo (USP), é professor associado da Faculdade de Filosofia, Ciências e Letras (FFCL) da USP, campus Ribeirão Preto.

mvcunha@yahoo.com

Recebido em 10 de fevereiro de 2012.

Aprovado em 7 de novembro de 2012. 